\title{
The Influence of Personal Factors on Youth Entrepreneurship - A Study Based on the Investigation of Guangzhou College Students
}

\author{
Jin $\mathrm{Wu}^{*}, \mathrm{Yi}$ Lin \\ Business School, Nanfang College of Sun Yat-Sen University, Guangzhou, China \\ Email: ruojincn@126.com
}

\begin{abstract}
In this study, we attempted to study the influence of individual factors such as the level of intelligence, past self-employment experience, and past work experience of Chinese college students on their decision to decide whether or not to take entrepreneurship as a career choice after graduation. Based on the quantitative analysis method, we collected the data of 600 young students from different courses in final year from a university in Guangzhou. The target population for this study was 22-23 years of age. The ratio of male to female was 55 and 45, respectively. Data were analyzed using cross tabulation and chi-square test. The results show that past self-employment experiences have a negative impact on students' entrepreneurial tendencies. There is no relationship between work experience and entrepreneurial tendencies. Students with higher scores in intelligence are considered to have no entrepreneurial tendency or very few entrepreneurial tendencies.
\end{abstract}

Keywords: Entrepreneurship, personal factors, career intention, entrepreneurial tendency

\section{Introduction}

Since General Secretary Xi Jinping proposed that China's economic development has entered the "new normal", the State Council has made a major strategic plan for mass entrepreneurship and innovation. Governments at all levels have recognized that the key to building prosperity and stimulating regional growth is to promote entrepreneurship among people, especially the youth. Youth entrepreneurship has become an area of interest for research scholars and the major development issue for the government. Promoting youth entrepreneurship not only helps reduce unemployment, but more importantly, it allows the youth to understand that they do not need to wait for jobs offered by others, but create their own future by starting their own company. As the southern gate of China, Guangzhou has a high degree of openness to the outside world, a large financial market, a strong atmosphere of innovation, and attracts many talents and enterprises in new technologies and industries. The Guangzhou Municipal Government has proposed a series of incentives to encourage college students to start businesses. For example, in the first five years of graduation, college students will enjoy $100 \%$ rent subsidy for the first year, $50 \%$ rent subsidy for the second year, and $30 \%$ rent subsidy for the third year. College students can apply for a 50,000-200,000 small secured loan for starting business. Under the self-employment of college students, they can relax the registration conditions, apply for trial operation, and can reduce the administrative fees such as registration and licenses within three years. Although these measures have attracted a large number of entrepreneurs to start a business to a certain extent, there is still a certain gap between the enthusiasm of college students for entrepreneurship and the level of foreign developed countries and regions. According to the annual report on the employment quality of college graduates released by the Guangdong Provincial Department of Education in 2017, the number of self-employed college students in Guangdong is only $0.38 \%$ of the number of graduates in the same year, while it's $20 \%-30 \%$ in the developed foreign countries. Studies have shown that the factors that affect college students' entrepreneurship are mainly lack of capital (Xing Nan, 2010; Wei Wei, Li Qiang, 2013), no prior knowledge (Li Guoyan, Li Nan, 2014) and lack of guidance (Yu Ruiling, 2006). Those college students who cannot be employed immediately for various reasons are a major social problem. If they are not resolved and controlled in time, they may bring greater risks to the local government. This study is to investigate the impact of personal factors on college students' entrepreneurial tendencies, such as prior experience, education, and intelligence. Lots of experts and scholars have demonstrated the important role of personal factors in entrepreneurship, but the data from the perspective of youth is still missing. There is currently a lack of accurate and systematic data on 
college students' personal entrepreneurship. That's why this paper attempts to understand the personal factors that influence young students' career choices, especially in terms of entrepreneurship.

\section{$2 \quad$ Literature Review}

The literature review of this study includes three parts. The first part includes the impact and research of individuals in their past entrepreneurial experiences. The second deals with a literature review of the impact of past work experience on entrepreneurship. The third one includes a summary of the research on the impact of personal intelligence on entrepreneurial development.

Studies have shown that individuals' past business experience affects their decision making and business performance (Dyke et al, 1992). In exploring the reasons for the choice of entrepreneurship, this is a clear indication that past business experience (An Ning, Wang Hongqi, 2011), relationship network (Ellis, 2011) and entrepreneurship role model (Liu Chen, 2014; Zhang Li, 2016) is very important. If the family and friends around the individual choose to start business, then they will be exposed to the information of various entrepreneurs and understand the entrepreneurial model, then they are more entrepreneurial (Cooper, Dunkelberg, 1984). The willingness to start a business and the identification of entrepreneurial opportunities are necessary for entrepreneurship. These two necessary conditions are constantly enhanced and accumulated in the entrepreneurial process. Situational perceptions of individuals based on past and existing experiences can influence their entrepreneurial intent (Shapero, Sokol, 2009). There is also a close relationship between previous entrepreneurial experience and self-efficacy. Previous entrepreneurial experiences lead to an increase in entrepreneurial self-efficacy. That's because previous entrepreneurial experiences provide role models and practical learning opportunities (Zhang Li, 2016). Entrepreneurial tendencies are considered to be related to previous entrepreneurial experience by most scholars. But many scholars believe that when college students choose to start a business, the previous entrepreneurial experience has a negative correlation with experience and entrepreneurial intention. If students have relatively little previous entrepreneurial experience, they will be more likely to start a business (McStay, 2008). Another survey of business students shows that the impact of previous entrepreneurial experiences on business students' entrepreneurial intentions is very small (Nishantha, 2009). Most of these studies come from the contributions of foreign scholars. When the research object is changed to Chinese university students, does the previous entrepreneurial experience have influence on the entrepreneurial tendency? Based on the above thinking, the first hypothesis of this paper has been proposed.

Hypothesis 1: Previous Entrepreneurial Experience Has a Negative Impact on the Tendency of Chinese College Students to Start a Business

There are also many scholars who believe that work experience will affect the individual's choice of entrepreneurship as a career choice to a certain extent, and sufficient work experience will help to form the competitiveness of individuals in entrepreneurship to a certain extent (Yang Jun, Xue Hongzhi , Niu Fang, 2011). For example, previous work experience can improve an individual's skills and abilities, especially for the identification of business opportunities (Zhang Xiuyan, Yan Weihong, Li Zehui, 2017). The innovation that reflects one's overall ability depends to a large extent on whether they have received a good education and previous management experience (Maxwell, Westerfield (2002). For new companies just formed, entrepreneurs' previous industry experience can help companies build their own relationship networks (Yang Jun, 2012). If the entrepreneur's previous industry and the industry he started to own are of the same type, it can contribute to the rapid development of the company (Samuelsson, 2009). However, college students do not have more opportunities to accumulate work experience in the school. So, when starting a business, work experience has nothing to do with the entrepreneurial tendency of them.

Hypothesis 2: Previous Work Experience Has No Effect on the Propensity of Students to Start a Business

Intelligence is the comprehensive energy that a person understands and deals with the world around him (Wechsler, 1941). It also includes the potential of a person (Gardner, 1993). This potential will be triggered by certain cultures, opportunities and values. Does the intellectual factor have an impact on entrepreneurship? Contemporary scholars classify intellectual factors to explore their relationship with entrepreneurship one by one. For example, the influence of social intelligence and technical intelligence is 
greater for entrepreneurs, but the impact of mathematics and verbal ability is greater for ordinary employees (Hartog et al., 2010). Creative intelligence is a key indicator for predicting the success of a startup for the company based on technological competition (Shane, Venkataraman, 2000). Practical wisdom also has a positive effect on the advancement of the entrepreneurial process (Baum et al., 2001). According to the above analysis, we can see that the research on the impact of academic intelligence on entrepreneurial intentions is still little. Some existing research shows that people's IQ level has a direct relationship with self-employment tendency. Professor Winden and Wit (1989) at the University of Amsterdam in the Netherlands have passed an empirical analysis that the possibility of self-employment is mainly determined by the income gap between self-employment and paid employment. People with a relatively high IQ score measured at the age of 12 will have a positive impact on late self-employment tendencies. A recent study found through the survey of founders from companies in different industries that their academic performance is at the upper-middle level in both middle school and university (Wadhwa, Rissing, 2010). Therefore, it can be seen that academic intelligence has greatly affected people's entrepreneurship. However, these data can be consistent with China's national conditions and require further investigation and research. To fill this gap, the third hypothesis of this paper is as below:

Hypothesis 3: Students' Academic Intelligence Has a Positive Influence on Entrepreneurial Tendencies

\section{$3 \quad$ Tests and Results}

We used a quantitative research method for data analysis, and the author designed a self-administered questionnaire as the main data collection tool. The research goal is the senior students at a university in Guangzhou. Target respondents total 600 people.

Hypothesis 1: Previous Entrepreneurial Experience Has a Negative Impact on the Tendency of Chinese College Students to Start a Business

To detect the above assumptions, the authors directly ask if they have previous entrepreneurial experience and summarize the results of the responses in a cross-tabulation (Table 1).

Table 1. Previous Entrepreneurial Experience and Entrepreneurial Tendencies

\begin{tabular}{llccc}
\hline & & \multicolumn{2}{c}{ Previous entrepreneurial experience } & \multirow{2}{*}{ Amount } \\
\cline { 3 - 4 } & & Yes & No & \\
\hline \multirow{2}{*}{ Employment } & Entrepreneurship & 15 & 21 & 36 \\
tendency after & Employed & 32 & 420 & 452 \\
graduation & Further education & 10 & 52 & 62 \\
& No decision & 5 & 45 & 50 \\
\hline Amount & & 62 & 538 & 600 \\
\hline
\end{tabular}

From the table, it can be seen that 62 of the 600 students have previous entrepreneurial experience, while the remaining 538 students have no experience. Of the 62 students with self-employment experience, only $24.1 \%(15 / 62)$ were willing to start a business after graduation, while more than half of the students. That is $51.6 \%(32 / 62)$ were willing to seek employment in the community. In addition, 16.1\% (10/62) of the students and $8 \%(5 / 62)$ of the students were willing to continue their studies or have no decision yet. In order to better explore the relationship between previous entrepreneurial experience and entrepreneurial tendencies, the author chose the chi-square test to verify.

Table 2. Chi-square Test (Previous Entrepreneurial Experience and Entrepreneurial Inclination)

\begin{tabular}{lccc}
\hline & value & df & Gradual progress Sig. (Bilateral) \\
\hline Pearson Chi-square & 24.181 & 3 & .013 \\
Likelihood ratio & 4.202 & 3 & .040 \\
Linear and linear combination & -2.532 & 1 & .002 \\
N in the effective case & 600 & & \\
\hline
\end{tabular}


The above table is the result of the chi-square test. The significance of the significance and likelihood ratio of Pearson chi-square is 0.013 , and 0.040 , both less than 0.05 . The significance test is passed, which indicates that there is a significant correlation between the two variables. The linear and linear combination has a value of -2.532 , indicating that previous entrepreneurial experience has a negative impact on college students' entrepreneurial tendencies.

$$
\chi_{\text {cal }}^{2}=24.181 \quad \chi_{t a b(3,0.05)}^{2}=5.794
$$

Hypothesis 2: Previous Work Experience Has No Effect on the Propensity of Students to Start a Business

To demonstrate whether prior work experience has an impact on entrepreneurial propensity, the author first classifies students according to the standard of working years, and 600 students are divided into five groups. The first group, students have no work experience. The second group, with one year of work experience. The third, with one to two years of work experience. The fourth, with two to three years of work experience. The fifth group, with more than three years of work experience. See Table 3 for specific data.

Table 3. Work Experience and Entrepreneurial Inclination

\begin{tabular}{llcccccc}
\hline & & \multicolumn{3}{c}{ Work Experience } & Amount \\
\cline { 3 - 7 } & & $1^{\text {st }}$ group & $2^{\text {nd }}$ group & $3^{\text {rd }}$ group & $4^{\text {th }}$ group & $5^{\text {th }}$ group & \\
\hline Work & Entrepreneurship & 25 & 8 & 2 & 1 & 0 & 36 \\
tendency & Employment & 430 & 20 & 2 & 0 & 0 & 452 \\
after & Further education & 51 & 7 & 3 & 1 & 0 & 62 \\
graduation & No decision & 46 & 3 & 1 & 0 & 0 & 50 \\
\hline Amount & & 552 & 38 & 8 & 2 & 0 & 600 \\
\hline
\end{tabular}

From the chart, it can be found that most students (92.1\%) do not have work experience, and among these students, only $4.5 \%(25 / 552)$ of students are willing to choose to start a business after graduation, and the vast majority of students are $77.8 \%$ (430/552) still willing to find a job. Besides, 9.2\% (51/552) and $8.3 \%(46 / 552)$ of the students chose to pursue further studies or did not make a decision at present. Among students (38 students) with one year of work experience, 21\% (8/38) of students choose to start a business, $52.6 \%(20 / 38)$ of students choose to find a job, and the other $18.4 \%(7 / 38)$ and $7.8 \%(3 / 38)$ of students choose to study or have not made any decisions. Among students with one to two years of work experience, $25 \%(2 / 8)$ of students are willing to start a business, $25 \%$ (2/8) of students choose to find a job, $37.5 \%$ choose to study, and $12.5 \%$ (1/8) students did not make decisions. It is worth noting that none of the 600 samples collected have worked for more than three years. To further verify the relationship between work experience and entrepreneurial tendencies, the author chose the chi-square test for verification.

Table 4. Chi-square Test (Work Experience and Entrepreneurial Inclination)

\begin{tabular}{lccc}
\hline & Value & df & Gradual progress Sig. (Bilateral) \\
\hline Pearson Chi-square & 16.839 & 9 & .065 \\
Likelihood ratio & 19.064 & 9 & .302 \\
Linear and linear combination & 1.448 & 1 & .229 \\
N in the effective case & 600 & & \\
\hline
\end{tabular}

The above table is the result of the chi-square test. The significance values of the Pearson chi-squares and the likelihood ratios were 0.065 and 0.302 , both greater than 0.05 , and did not pass the significance test, indicating that there is no significant correlation between the two variables. Previous work experience has no effect on the tendency of students to start a business.

$$
\chi_{c a l}^{2}=16.839 \quad \chi_{t a b(9,0.05)}^{2}=4.196
$$


Hypothesis 3: Students' Academic Intelligence Has a Positive Influence on Entrepreneurial Tendencies

In order to study the relationship between academic intelligence and entrepreneurial tendencies, the author divides the academic intelligence level of students into three grades. The university's four-year average score of 80 or above is excellent, indicating that the academic intelligence level is high. The average four-year university score between 70 and 80 is medium, indicating that the academic intelligence level is medium. The university's four-year average score is below 70, indicating that the academic intelligence level is low. See Table 5 for specific data.

Table 5. Academic Intelligence and Entrepreneurial Tendencies

\begin{tabular}{llcccc}
\hline & & \multicolumn{3}{c}{ Academic Intelligence Level } & \multirow{2}{*}{ Amount } \\
\cline { 3 - 5 } & & High & Medium & Low & \\
\hline Work & Entrepreneurship & 9 & 22 & 5 & 36 \\
tendency & Employment & 120 & 275 & 57 & 452 \\
after & Further Education & 45 & 14 & 3 & 62 \\
graduation & No decision & 35 & 10 & 5 & 50 \\
\hline Amount & & 209 & 321 & 70 & 600 \\
\hline
\end{tabular}

From the chart, it can be found that only 9 of the 209 students with good academic performance are willing to start a business after graduation, the proportion is $4.3 \%$. Up to $57.4 \%(120 / 209)$ of students are willing to choose to find a job, and $21.5 \%$ (45/209) and $16.7 \%(35 / 209)$ of students are willing to continue their studies or have not made the final decision. Among the 321 students with moderate academic performance, $6.8 \%(22 / 321)$ of students are willing to start their own businesses, while $85.6 \%(275 / 321)$ of them are willing to find a job, and $4.3 \%(14 / 321)$ and $3.1 \%(10 / 321)$ of students are willing to pursue further studies or have not made decisions at present. Among the 70 students with low academic scores, more than half of them are $81.4 \%$ (57/70) willing to find a job instead of starting a business. The author uses the chi-square test to detect the specific data as shown below to demonstrate the relationship between academic intelligence and entrepreneurial tendencies better.

Table 6. Chi-square Test (Academic Intelligence and Entrepreneurial tendencies)

\begin{tabular}{lccc}
\hline & Value & df & Gradual progress Sig. (Bilateral) \\
\hline Pearson Chi-square & 12.012 & 6 & .213 \\
Likelihood ratio & 12.462 & 6 & .188 \\
Linear and linear combination & 9.339 & 1 & .072 \\
N in the effective case & 199 & & \\
\hline
\end{tabular}

The above table is the result of the chi-square test. The significance of the Pearson chi-square and the likelihood ratio are 0.0213, and 0.188, respectively, both greater than 0.05. No significant test, which means that there is no significant difference between the two variables. So, academic performance has no effect on the tendency of students to start a business.

$$
\chi_{c a l}^{2}=12.462 \quad \chi_{t a b(6,0.05)}^{2}=3.691
$$

\section{Discussion}

Previous research has shown that personal past business experience will motivate them to choose entrepreneurship as their career development option. Previous entrepreneurial experience can be seen as an important motivating factor and contributing factor to re-entrepreneurship (An Ning, Wang Hongqi, 2011). However, according to the research in this paper, the previous entrepreneurial experience of college students did not affect their choice of entrepreneurship as their profession. Only a small percentage of students with prior entrepreneurial experience (15/62) are willing to continue their business after graduation. But more than half of students with creative experience are willing choose a job in society after graduation (32/62). The results of this study are consistent with the results of McStay (2008). Students 
who do not have a backup entrepreneurial experience are more willing to choose to start a business after graduation than those with entrepreneurial experience. Our research also fully demonstrates that students' previous work experience is not directly related to the choice of entrepreneurs after graduation. This result contradicts many existing research results. For example, Yang Jun, Xue Hongzhi, Niu Fang (2011) believe that work experience will also affect whether individuals take entrepreneurship as their career choice to a certain extent, and sufficient work experience will help to form individual competitiveness in business. The innovation that reflects one's overall ability depends to a large extent on whether they have received good education and previous management experience (Maxwell, Westerfield (2002). This result may be due to the particularity of our research objects. This study is based on the goal of college students. Only $6.3 \%$ $(38 / 600)$ of students have less than one year of work experience, $1.3 \%$ of students $(8 / 600)$ have one to two years of work experience, $0.3 \%(2 / 600)$ of students have more than two to three years of work experience, no students have more than three years of work experience. And a lot of research shows that entrepreneurs have accumulated many years of work experience before establishing their own company (Yan Shi, 2012). Therefore, a small amount of work experience has no effect on the student's entrepreneurial intention, it's invalid. Finally, the study also found that there is no direct relationship between the academic intelligence level of students and entrepreneurial intentions. Students who perform well in academic are often reluctant to choose to start a business. The tables show that only $4.3 \%(9 / 209)$ of students with good academic performance are willing to start their own business after graduation, while $57.4 \%(120 / 209)$ students are more willing to find a job. This is contrary to the findings of Winden and Wit (1989) and Wadhha and Rissing (2010).

\section{Conclusion}

In this paper, the author examines the personal factors of Chinese college students such as intelligence level, past self-employment experience, past work experience and their influence on whether to choose entrepreneurship as a career choice after graduation. We collected data from 600 young students from all majors in a university in Guangzhou. Results based on cross-listing and chi-square tests show that past self-employment experiences have a negative impact on students' entrepreneurial tendencies. There is no relationship between work experience and entrepreneurial tendencies. Students who score higher on the level of intelligence are considered to have no entrepreneurial inclination or few entrepreneurial tendencies. These research findings not only enrich the content of entrepreneurship, but also have practical significance in the context of the era when the state encourages college students to start their own businesses. The research object of this paper is the university students in Guangzhou. Today's research can expand the scope of the sample, thus find the differences in entrepreneurial tendencies of college students in different regions.

Acknowledgement. The project was supported by the Research Center for Cross-Border E-Commerce of the Belt and Road, industry university research platform, Nanfang College of Sun Yat-sen University.

\section{Reference}

1. Baum J R, Locke E A, Smith K G. A Multidimensional Model of Venture Growth.[J]. Academy of Management Journal, 2001, 44(2):292-303.

2. Cooper A C, Dunkelberg W C. Entrepreneurship and Paths to Business Ownership[J]. Strategic Management Journal, 1986, 7(1):53-68.

3. Dyke L S, Fischer E M, Reuber A R. An inter-industry examination of the impact of owner experience on firm performance[J]. Journal of Small Business Management, 1992, 30(4):72-87.

4. Ellis P D. Social ties and international entrepreneurship: Opportunities and constraints affecting firm internationalization[J]. Journal of International Business Studies, 2011, 42(1):99-127.

5. Gardner H. Multiple intelligences:, The theory in practice.[J]. 1993, 32(6):304

6. Hartog J, Praag M V, Sluis J V D. If You Are So Smart, Why Aren't You an Entrepreneur? Returns to Cognitive and Social Ability: Entrepreneurs Versus Employees[J]. Journal of Economics \& Management Strategy, 2010, 19(4):947-989.

7. Maxwell J R, Westerfield, D L. Technological entrepreneurism characteristics related to the adoption of innovative 
technology[J]. Sam Advanced Management Journal, 2002, :67(:1):9-21

8. Mcstay D. An investigation of undergraduate student self-employment intention and the impact of entrepreneurship education and previous entrepreneurial experience[J]. Sensors \& Actuators A Physical, 2008, 188(188):41-47.

9. Nishantha B. Influence of Personality Traits and Socio-demographic Background of Undergraduate Students on Motivation for Entrepreneurial Career : The Case of Sri Lanka[J]. Ryukoku Journal of Economic Studies, 2009, 49:71-82.

10. Samuelsson M. Modeling the Nascent Venture Opportunity Exploitation Process Across Time[J]. Social Science Electronic Publishing, 2009

11. Shane S, Venkataraman S. The Promise of Entrepreneurship As A Field of Study[J]. Academy of Management Review, 2000, 25(1):217-226.

12. Shapero A, Sokol L. The Social Dimensions of Entrepreneurship[J]. Social Science Electronic Publishing, 2009, 25(8):28

13. Wechsler D. The measurement of adult intelligence (2nd ed.).[J]. American Journal of Orthopsychiatry, 1941, $9(4): 808-812$

14. Wadhwa V, Freeman R B, Rissing B A. Education and Tech Entrepreneurship $[\mathrm{J}]$. Social Science Electronic Publishing, 2010, 5(2).

15. Wit G D, Winden F A A M V. An empirical analysis of self-employment in the Netherlands[J]. Small Business Economics, 1989, 1(4):263-272. 